\title{
Mathematical Model of Improved Reverse Charging of Wireless Internet Pricing Scheme in Servicing Multiple QoS
}

\author{
F M Puspita ${ }^{1 *}$, D R Nur ${ }^{2}$, A L Tanjung ${ }^{1}$, J Silaen $^{1}$, W Herlina ${ }^{3}$, and Yunita ${ }^{4}$ \\ ${ }^{I}$ Mathematics Department, Faculty of Mathematics and Natural Science, Sriwijaya University, Jl. Raya Palembang - \\ Prabumulih KM. 32 Indralaya Ogan Ilir 30662, Indonesia \\ ${ }^{2}$ Mathematics Department, Faculty of Mathematics and Natural Science, University of Lampung, Jl. Prof. Dr. Sumantri \\ Brojonegoro No. 1 Bandar Lampung, 35145, Indonesia \\ ${ }^{3}$ Mining Department, Faculty of Engineering, Sriwijaya University, Jl. Raya Palembang - Prabumulih KM. 32 Indralaya \\ Ogan Ilir 30662, Indonesia
}

${ }^{4}$ Informatics Engineering Department, Faculty of Computer Science, Sriwijaya University, Jl. Raya Palembang Prabumulih KM. 32 Indralaya Ogan Ilir 30662, Indonesia

*Email: fitrimayapuspita@unsri.ac.id

\author{
Article Information \\ Received: \\ 16 February 2019 \\ Received in revised form: \\ 18 April 2019 \\ Accepted: \\ 30 April 2019
}

Volume 1, Issue 2, December 2019

pp. $89-93$

CUniversitas Lampung
Abstract

This paper seeks to utilize the improved model of reverse charging scheme. Reverse charging basically is defined as a capability of stored network that replaces the network used when the network is suddenly shut down. In this paper, charging back on $3 G$ and $4 G$ network that is user automated platform, will change the access of $4 G$ to $3 G$ and on the contrary when platform conduct the hosting. This research was solved as a problem Mixed Integer Nonlinear Programming (MINLP) by LINGO 13.0. An optimal pricing scheme is applied to a local data server, including digilib traffic and mail traffic. The improved model of Reverse Charging is modified into 4 cases and formed by setting the base price $(\alpha)$ and service level $(\beta)$. Based on the analysis that has been done, the results of this study indicate that the reverse charging model can be utilized Internet Service Provider (ISP) to maximize profits and provide quality services for the user if compared to previous model without reverse charging scheme.

Keywords: improved model of revere charging scheme, MINLP, ISP, QoS, pricing scheme

\section{INTRODUCTION}

$\mathrm{T}$ he development of the Internet world is often be accelerated by the acquisition of information, business, education, social life, and even become a place of their own entertainment. The high internet users are increasing every year give a positive impact to the Internet service provider (ISP) as service providers must develop in each feature internet. ISP as a provider company should be able to provide the best quality service or Quality of Service (QoS) to the user. The service price and good quality certainly affect both the ISP in order to maximize profits [1].

Based on research [1-3] and advanced researchers from [4-6] research has been conducted on the network wired and wireless internet which use pricing utility function that focuses on the level of use and models of different packages. Bottleneck's problems occurs during the transfer of data where the number of data packets sent and received does not match, resulting in congestion of data transmission. This problem is solved by charging Internet model where the model is used when there is a transfer of redundant data that can be adjusted using the data package savings.

Pricing level model also involves Internet service QoS network and multi-service networks. The level of pricing needs and high demand will become a problem for ISPs. Then ISP applies bundle pricing strategy to minimize costs and maximize profits [7]. The service should pay attention to the level of satisfaction on the service consumption, utility function associated with the consumption level of satisfaction with the service so as to achieve maximum profit [8]. The marketing 
strategy using the bundle pricing by combining two or more products into one, as well as to overcome the problems will be diversity and unpredictability of the price level of consumer demand that has been discussed previously [9].

Internet network problems pricing schemes need to consider methods of storage and physical custody. Some research $[10,11]$ discuss the pricing scheme of the Internet by exploiting the model of cloud computing and cloud radio access network (C-RAN). Cloud computing is a model that allows service providers to access information without limits in time or place and is only available when is needed by users [12]. While the C-RAN used the base station exclusively (BTS) stand-alone or centrally connected to the antenna cell to process the radio signals (RRHS) of processing digital (BBU) and send it to the core network / radio antenna towers [13].

Reverse charging method is the introduction of service quality and one ISP-to-ISP customers only do speed of access of the user, the charging scheme focuses on charging, so it is not allowed others to do the reverse charging. For high-speed data transmission with the necessary applications to connect customers to the Internet that would allow a different quality (QoS) [14].

Other method of charging has a benefit for subscription fees and the cost of sessions each in turn consists of component set-up and recurring component to the user [15]. In reverse charging model, collections of other users are able to reduce congestion and get the satisfaction of users [16]. Reverse charging is focused on $3 \mathrm{G}$ and $4 \mathrm{G}$ networks turnover while doing the hosting. This situation will be replaced automatically influenced by the distance of the user to the main antenna. To adjust the price, ISPs must fully understand that the QoS affects the willingness of users to use the product but ISPs cannot improve the quality of service indefinitely because of limited network resources such as bandwidth, capacity, delay, jitter and utilization.

This study attempts to further study and analyze the network-pricing scheme by applying reverse charging models. Reverse charging models themselves will be simplified into a mathematical model to determine the objective function and constraint functions. MINLP (Mixed Integer Linear Programming) is a linear programming model to optimize goal. In MINLP process, the objective function is determined first. The optimal solution of MINLP lies in a majority of decision variable to be integers. This research uses 4 cases as a comparison of the data result and is applied to local data server namely digital library and information systems.

\section{Materials AND MethodS}

The calculation of the amount of bandwidth consumption will be settled using optimization model of MINLP in which LINGO 13.0 will simulate formulas and research results. The optimization model is established based on parameters and variables that will be used to solve optimization problems. An pricing scheme is aplied a local data server, including digilib and mail traffics.

\section{RESULTS AND DISCUSSIONS}

Results should be presented in tables and figures in order to highlight all findings. Author should compare their findings to other published articles. All tables and figures should be cited or referred in the body text.

Detail information regarding the manuscript preparation is presented as follows.

Basically, the optimization model used is based[5]. The proposed improved model is as follows. First case is when $\alpha$ and $\beta$ are fixed, based on eq. (1).

$$
\operatorname{Max} R=\sum_{i=1}^{2}\left(\alpha+\beta I_{I}\right) p_{i} x_{i}
$$

Subject to:

$$
\begin{aligned}
& I_{i} d_{i} x_{i} \leq a_{i} C, i=1,2 \\
& \sum_{i=1}^{2} I_{i} d_{i} x_{i} \leq a_{i} C, i=1,2 \\
& \sum_{i=1}^{2} a_{i}=1, i=1,2 \\
& m_{i} \leq I_{i} \leq 1, i=1,2 \\
& 0 \leq x_{i} \leq n_{i}, i=1,2 \\
& \{\text { xi } \text { integer, } i=1,2
\end{aligned}
$$

Second case when $\alpha$ is fixed and $\beta$ varies:

$\operatorname{Max} R=\sum_{i=1}^{2}\left(\alpha+\beta_{i} I_{I}\right) p_{i} x_{i}$

With subject to constraint of equation (2) to (7). It may be added new constraints as follows:

$$
\begin{aligned}
& \beta_{i} I_{i} \geq \beta_{i-1} I_{i-1}, i>1 \\
& I_{i} \leq \beta_{i} \leq b_{i}, i=1,2
\end{aligned}
$$

Further case for $\alpha$ is fixed and $\beta$ varies:

$$
\operatorname{Max} R=\sum_{i=1}^{2}\left(\alpha_{i}+\beta_{i} I_{I}\right) p_{i} x_{i}
$$

With subject to constraint of equation (2) to (7) and equation (9) to (10), it may consider new constraints as follows:

$$
\begin{aligned}
& \alpha_{i}+\beta_{i} I_{i} \geq \alpha_{i-1} \beta_{i-1}, i>1 \\
& c_{i} \leq \alpha_{i} \leq g_{i}, i=1,2
\end{aligned}
$$

Last case is for $\alpha$ is fixed and $\beta$ varies:

$$
\operatorname{Max} R=\sum_{i=1}^{2}\left(\alpha_{i}+\beta I_{I}\right) p_{i} x_{i}
$$

With subject to constraints of equations (2) to (8) and eq. (14), it may added new constraints as follows:

$$
\alpha_{i}+I_{i} \geq \alpha_{i-1}+I_{i-1}, i>1
$$


In the following calculation, four cases from the above model will be discussed, each case will be distinguished based on the selection of parameters and variables on the function of certain constraints.

\section{A. Case 1}

On the case 1 , base price of service is $(\alpha)$ selected as parameter and quality premium $(\beta)$ is also a parameter in which the Table 1 and 2 presents the parameter and variables, respectively. The parameters and variables are set to satisfy all the condition requires by the Model (1) to (7).

Table 1. Parameter for Each Improved Model for Case 1

\begin{tabular}{|c|l|}
\hline Symbol & \multicolumn{1}{c|}{ Definition } \\
\hline$\alpha$ & Base price \\
\hline$\beta$ & Quality premium \\
\hline$C$ & Total capacity \\
\hline$p_{i}$ & User price of service $i$ \\
\hline$d_{i}$ & $\begin{array}{l}\text { Capacity needed to provide full QoS unit of } \\
\text { service } i\end{array}$ \\
\hline$m_{i}$ & Minimum level of QoS for service $i$ \\
\hline$n_{i}$ & Maximum number of users for service $i$ \\
\hline
\end{tabular}

Table 2. Variables for Each Improved Model for Case 1

\begin{tabular}{|c|l|}
\hline Symbol & \multicolumn{1}{c|}{ Definition } \\
\hline$I_{i}$ & QoS level for service $i$ \\
\hline$X_{i}$ & Number of users of $i$ \\
\hline$a_{i}$ & Allocation of network $i$ \\
\hline
\end{tabular}

\section{B. Case 2}

On the Case 2, base price of service $i$ is $(\alpha)$ selected as parameter and quality premium $i\left(\beta_{i}\right)$ selected as variable in which the Table 3 and 4 presents the parameter and variables, respectively. The parameters and variables are set to satisfy all condition required by the constraints of (8) to (10).

Table 3. Parameter for Each Improved Model for Case 2

\begin{tabular}{|c|l|}
\hline Symbol & \multicolumn{1}{c|}{ Definition } \\
\hline$\alpha$ & Base price \\
\hline$C$ & Total capacity \\
\hline$p_{i}$ & User price of service $i$ \\
\hline$d_{i}$ & $\begin{array}{l}\text { Capacity needed to provide full QoS unit of } \\
\text { service } i\end{array}$ \\
\hline$m_{i}$ & Minimum level of QoS for service $i$ \\
\hline$n_{i}$ & Maximum number of users for service $i$ \\
\hline$b_{i}$ & Maximum of quality premium for service $i$ \\
\hline
\end{tabular}

Table 4. Variables for Each Improved Model for Case 2

\begin{tabular}{|c|l|}
\hline Symbol & \multicolumn{1}{c|}{ Definition } \\
\hline$I_{i}$ & QoS level for service $i$ \\
\hline$X_{i}$ & Number of users of $i$ \\
\hline$a_{i}$ & Allocation of network $i$ \\
\hline$\beta_{i}$ & Quality premium for service $i$ \\
\hline
\end{tabular}

Table 5. Parameter for Each Improved Model for Case 3

\begin{tabular}{|c|l|}
\hline Symbol & \multicolumn{1}{|c|}{ Definition } \\
\hline$C$ & Total capacity \\
\hline$p_{i}$ & User price of service $i$ \\
\hline$d_{i}$ & $\begin{array}{l}\text { Capacity needed to provide full QoS unit of } \\
\text { service } i\end{array}$ \\
\hline$m_{i}$ & Minimum level of QoS for service $i$ \\
\hline$n_{i}$ & Maximum number of users for service $i$ \\
\hline$b_{i}$ & Maximum quality premium value for service $i$ \\
\hline$g_{i}$ & Maximum level of QoS for service $i$ \\
\hline$c_{i}$ & Minimum quality premium value for service $i$ \\
\hline
\end{tabular}

\section{Case 3}

On case 3 , base price of service $i$ is $\left(\alpha_{i}\right)$ selected as variables and quality premium $i\left(\beta_{i}\right)$ is also selected as variable presented on Table 5 and 6 of the parameter and variables respectively. The parameters and variables are set to satisfy all the condition requires by the constraints (11) to (13).

Table 6. Variables for Each Improved Model for Case 3

\begin{tabular}{|c|l|}
\hline Symbol & \multicolumn{1}{c|}{ Definition } \\
\hline$I_{i}$ & QoS level for service $i$ \\
\hline$X_{i}$ & Number of users of $i$ \\
\hline$a_{i}$ & Allocation of network $i$ \\
\hline$\beta_{i}$ & Quality premium for service $i$ \\
\hline$\alpha_{i}$ & Base price for service $i$ \\
\hline
\end{tabular}

\section{Case 4}

On the case 4 , base price of service $i$ is $\left(\alpha_{i}\right)$ selected as variables and quality premium $(\beta)$ selected as parameter in which the Table 7 and 8 presents the parameter and variables respectively. The parameters and variables are set to satisfy all the condition requires by the equations (14) to (15).

Table 7. Parameter for Each Improved Model for Case 4

\begin{tabular}{|c|l|}
\hline Symbol & \multicolumn{1}{c|}{ Definition } \\
\hline$\beta$ & Quality Premium \\
\hline$C$ & Total Capacity \\
\hline$p_{i}$ & User price of service $i$ \\
\hline$d_{i}$ & $\begin{array}{l}\text { Capacity needed to provide full QoS unit of } \\
\text { service } i\end{array}$ \\
\hline$m_{i}$ & Minimum level of QoS for service $i$ \\
\hline$n_{i}$ & Maximum number of users for service $i$ \\
\hline$b_{i}$ & Maximum quality premium value for service $i$ \\
\hline$g_{i}$ & Maximum level of QoS for service $i$ \\
\hline$c_{i}$ & Minimum quality premium value for service $i$ \\
\hline
\end{tabular}

Table 8. Variabel for Each Improved Model for Case 4

\begin{tabular}{|c|l|}
\hline Symbol & \multicolumn{1}{c|}{ Definition } \\
\hline$I_{i}$ & QoS level for service $i$ \\
\hline$X_{i}$ & Number of users of $i$ \\
\hline$a_{i}$ & Allocation of network $i$ \\
\hline$\alpha_{i}$ & Base price of service $i$ \\
\hline
\end{tabular}


To solve the models presented in Eq. (1)-(7), we give the numerical example of parameters and it is solved numerically by using LINGO 13.0. In Table 9, we give the numerical value of the parameters.

The solver status for each case is obtained like stated in Table 10. For the decision variables, the solution for each case is presented in Table 11.

Table 9. Numerical Example

\begin{tabular}{|c|c|c|c|}
\hline Parameter & Value & Parameter & Value \\
\hline$\alpha$ & 0.1 & $n_{1}$ & 10 \\
\hline$\beta$ & 0.5 & $n_{2}$ & 10 \\
\hline$C$ & 350000 & $b_{1}$ & 0.5 \\
\hline$p_{1}$ & 45 & $b_{2}$ & 0.5 \\
\hline$p_{2}$ & 15 & $m_{1}$ & 0.01 \\
\hline$g_{1}$ & 1.5 & $m_{2}$ & 0.01 \\
\hline$g_{2}$ & 1.5 & $c_{2}$ & 0 \\
\hline$c_{1}$ & 0 & $d_{1}$ & 4.24 \\
\hline & & $d_{2}$ & 1.87 \\
\hline
\end{tabular}

Table 10. Solver Status

\begin{tabular}{|c|c|c|c|c|}
\hline \multirow{2}{*}{$\begin{array}{c}\text { Solver } \\
\text { Status }\end{array}$} & \multicolumn{4}{|c|}{ Value } \\
\cline { 2 - 5 } $\begin{array}{c}\text { Model } \\
\text { Class }\end{array}$ & MINLP & Case 2 & Case 3 & Case 4 \\
\hline State & $\begin{array}{c}\text { Local } \\
\text { Optimal }\end{array}$ & $\begin{array}{c}\text { Local } \\
\text { Optimal }\end{array}$ & $\begin{array}{c}\text { Local } \\
\text { Optimal }\end{array}$ & $\begin{array}{c}\text { Local } \\
\text { Optimal }\end{array}$ \\
\hline Objective & 270 & 337.5 & 787.5 & 450 \\
\hline Iterations & 27 & 29 & 8 & 36 \\
\hline
\end{tabular}

Table 11. Solution Models

\begin{tabular}{|c|c|c|c|c|}
\hline \multirow{2}{*}{ Variable } & \multicolumn{5}{|c|}{ Value } \\
\cline { 2 - 5 } & Case 1 & Case 2 & Case 3 & Case 4 \\
\hline$I_{1}$ & 1 & 0.5 & 0.5 & 1 \\
\hline$I_{2}$ & 0.505 & 0.5 & 0.5 & 1 \\
\hline$X_{1}$ & 10 & 10 & 10 & 10 \\
\hline$X_{2}$ & 0 & 0 & 0 & 0 \\
\hline$a_{1}$ & 1 & 1 & 1 & 1 \\
\hline$a_{2}$ & 0 & 0 & 0 & 0 \\
\hline$\alpha_{1}$ & - & - & 1.5 & 0.5 \\
\hline$\alpha_{2}$ & - & - & 1.5 & 0.5 \\
\hline$\beta_{1}$ & - & 0.5 & 0 & - \\
\hline$\beta_{2}$ & - & 0.5 & 0.5 & - \\
\hline
\end{tabular}

Table 1 to 8 define each variable and parameters and shows the differences for each case base on available possibility. The 10-11 Table shows the result of solving the model with 4 existing cases using LINGO program. In case 1 optimization model is MINLP with optimum result of 270. In case 1 , base price of service is $(\alpha)$ selected as parameter and quality premium $(\beta)$ is also a parameter. In case 2 optimization model is MINLP with optimum result of 337.5 .

In case 2, base price of service $i$ is $(\alpha)$ selected as parameter and quality premium $i\left(\beta_{i}\right)$ selected as variable. In case 3 optimization model is MINLP with optimum result of 787.5. In case 3, base price of service $i$ is $\left(\alpha_{i}\right)$ selected as variables and quality premium $i\left(\beta_{i}\right)$ is also selected as variable.

Optimization model is MINLP with optimum result of 450. The optimization model is MINLP with optimum result of 787.5. In the case 4 , base price of service $i$ is $\left(\alpha_{i}\right)$ selected as variables and quality premium $(\beta)$ selected as parameter.

\section{CONClusions}

Prepare the conclusion in a single paragraph without reference. Conclusion should be prepared in a complete sentence and paragraph without numbers or pointers. Please inform the future study or application of the current findings. Based on the solution of reverse charging model using LINGO software, the optimum result obtained from the model is that in case 3 the optimum result is 787.5 unity of time. Of our four cases we obtained same type of model which is MINLP.

\section{ACKNOWLEDGMENT}

The research leading to this study is financially supported by Sriwijaya University for support through Hibah Penelitian Unggulan Kompetitif Tahun 2018.

\section{REFERENCES}

[1] J. Byun and S. Chatterjee. (2004). A strategic pricing for quality of service (QoS) network business. Proceedings of $10^{\text {th }}$ Americas Conference on Information Systems, New York, USA, 2004.

[2] S. Sain and S. Herpers. (2003). Profit Maximisation in Multi Service Network an Optimisation Model. Proceedings11th European Conference on Information System ECIS 2003, Naples, Italy, 2003.

[3] W. Yang, "Pricing Network Resources in Differentiated Service Networks," School of electrical and Computer Engineering, Georgia Institute of Technology, 2004, pp. $1-111$

[4] F. M. Puspita, K. Seman, B. M. Taib, and Z. Shafii. (2013). Improved Models of Internet Charging Scheme of Multi bottleneck Links in Multi QoS Networks, Australian Journal of Basic and Applied Sciences. Vol. 7 (7) pp. 928-937.

[5] F. M. Puspita, K. Seman, B. M. Taib, and Z. Shafii. (2013). Improved Models of Internet Charging Scheme of Single Bottleneck Link in Multi QoS Networks. Journal of Applied Sciences, Vol. 13 (4) pp.572-579.

[6] F. M. Puspita and M. Ulfa. (2016). The New Approach of Bundle-Pricing Scheme Models by Using Branch and Bound Solver. Proceedings of The 1st International Conference on South East Asia Studies (ICSEAS 2016) Universitas Trilogi, Jakarta, Indonesia.

[7] S. Viswanathan and G. Anandalingam. (2005). Pricing strategies for information goods. Sadhana. Vol. 30 (23), pp. 257-274. 
[8] X. Wang and H. Schulzrinne. (2001). Pricing network resources for adaptive applications in a differentiated services network. Proceedings of IEEE INFOCOM 2001 - The Conference on Computer Communications IEEE INFOCOM 2001, Anchorage, AK, USA. IEEE Explorer, pp. 1-11.

[9] S. Wu, L. Hitt, P. Chen, and G. Anandalingam. (2008). Customized Bundle Pricing for Information Goods: A Nonlinear Mixed-Integer Programming Approach. Management Science. Vol. 54 (3), pp. 608-622.

[10] Indrawati, F. M. Puspita, N. Inosensius, and S. Erlita. (2018). Improved Cloud Computing Model of Bandwidth Efficiency Consumtion Internet Pricing Sceme. Proceeding of IEEE AMIKOM Conference, Yogyakarta, 2018.

[11] S. Stremersch and G. Tellis. (2002). Strategic Bundling of Products and prices:A New Synthesis for Marketing. J. Marketing. Vol. 66 (1), pp. 55-72.

[12] G. Lodi, F. Panzieri, D. Rossi, and E. Turinni. (2007). SLA-Driven Clustering of QoS Aware Aplication Servers. IEEE Trans. on Soft Eng. Vol. 33 (3), pp. 186197.
[13] S. Blake, D. Black, M. Carlson, E . Davies, Z. Wang and W. Weiss. (1998). Architecture for Differentiated Services. RFC 2475, Network Working Group, pp. 136.

[14] Indrawati, F. M. Puspita, Inosensius.N, S. Erlita. (2017). Improved Cloud Radio Access Network (C-RAN) Model of Bandwidth Efficiency Consumtion Internet Pricing Sceme. Proceeding of Annual Research Seminar, Palembang, Indoneisa, 2017.

[15] R. A. M. Sprenkels R. Parhonyi, A. Pras, B. J. van Beijnum, and B. L. de Goede. (2000). Reverse Charging in the Internet an Architecture for a new Accounting Scheme for Internet Traffic. IEEE Workshop on IPOriented Operations \& Management (IPOM2000) Cracow, Poland. pp. 1-9.

[16] Y. L. M. Peng, J. L. J. Jiang, and C. Wang. (2015). Heterogenesus cloud radio access network: A new perspective for enhancing the spectral and energy efficiensis. IEEE Wireless Commun. Vol. 21 (6), pp. 120. 